\title{
New original decorative specimen of common bird cherry
}

\author{
Vladimir Simagin*, and Anna Lokteva \\ Central Siberian Botanical Garden SB RAS, 630090 Novosibirsk, Russia
}

\begin{abstract}
The northern regions of Russia are characterized by a relatively poor composition of the cultural dendroflora, that due to harsh climatic conditions. To create resistant varieties, it is necessary to attract local highly winter-resistant forms and on their. The northern regions of Russia are characterized by a relatively poor composition of the cultural dendroflora, that due to harsh climatic conditions. To create resistant varieties, it is necessary to attract local highly winter-resistant forms and on their basis to obtain hybrids with foreign species and new samples of Prunus padus L. with better ornamental characteristic to crossing with them.
\end{abstract}

\section{Introduction}

Bird cherry (Prunus padus L.) grows widely in the forest and forest-steppe zones, which make up most of the territory of Russia. She is one of the favorite plants for decorative landscaping among the local population. Our research showed a wide intraspecific variability of this species in many decorative traits and the prospects for creating new highly decorative varieties on its basis by intraspecific selection and interspecific hybridization.

\section{Material and methods}

The work was carried out in the Central Siberian Botanical Garden of the SB RAS (CSBG SB RAS) on the basis of the bioresource scientific collection "Collections of living plants in open and closed ground", UNU No. USU 440534.

In the abandoned village of Peshkovskoe, Ubinsky district, of Novosibirsk region, A.V. Loktevoy found an adherent broken branch of bird cherry near an abandoned estate.

\section{Results and discussion}

In Western European dendrological summaries [1,2] there is little information about the creation of decorative genotypes there, instead of the difference from many other cultures. Mentioned Only the form of Plena, varieties Waterery, Alberty and Colorata, are

\footnotetext{
* Corresponding author: simagin48@ mail.ru
} 
mentionadea there, white-flowered varieties are noticeably inferior in decorativeness to many wild Siberian plants. Therefore, the search and selection in nature for new, more decorative in terms of quality of flowers, genotypes and original mutations is an actual task.

This branch had very small, narrow, densely spaced leaves that were noticeably different from the original plant. There were also small white flowers in short racemes. A part of the branch was transferred to the collection of the Central Siberian Botanical Garden of the SB RAS. An independent plant had very weak branching, short, very thick branches with closely spaced internodes (Fig.). [3] There were also small white flowers in short racemes with close flowers. Part of the branch was vegetatively transferred to the collection of the CSBS SB RAS. The independent plant had very weak branching, short, very thick branches with a close arrangement of leaves. The flowers are small, without noticeable morphological disorders, small fruits with germinating seeds are tied. This genotype has a high survival rate when rooted by green cuttings in film shelters with installations of regular small-drop spraying, forming long roots of the first and second order. For several years, the spring copulation of cuttings of this sample into the crown of other genotypes was unsuccessful [4].
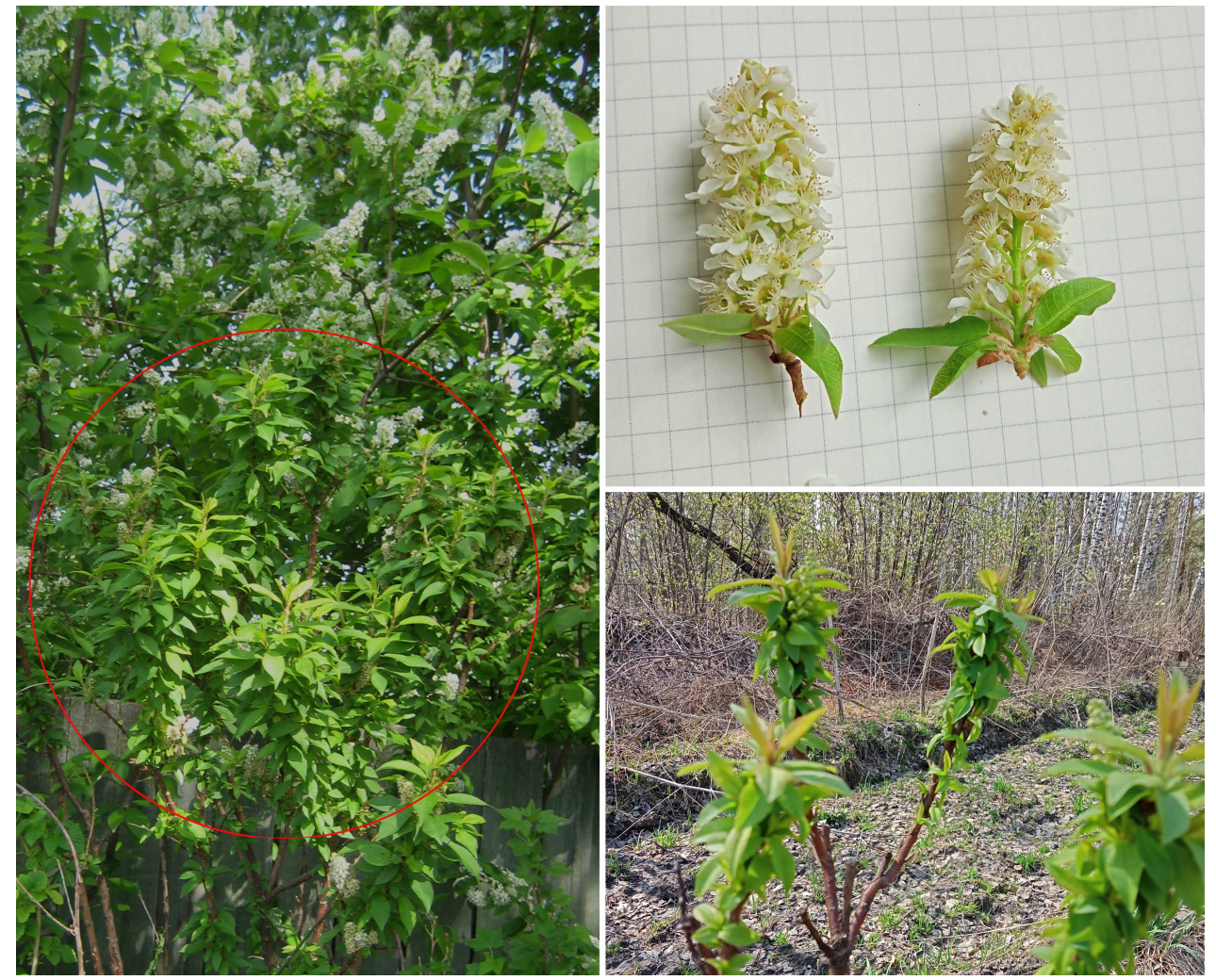

Fig. New original plant bird cherry. Flowers. Adherent mutation brunch.

\section{Conclusion}

In our opinion, this superspuric plant, due to its low reproduction rate, is not very suitable for mass distribution, but it is undoubtedly promising as a genetic source for combining its growth characteristics with valuable signs of color of leaves and flowers, which make it possible to create new original decorative qualities. 
Acknowledgements. This work was supported by the state project number: AAAA-A21121011290027-6 for the Central Siberian Botanical Garden (CSBG) SB RAS). Materials of the bioresource scientific collection of the CSBG SB RAS "Collections of living plants in open and closed ground", USU No. 440534 were used.

\section{References}

1. W. J. Bean, Trees and shrubs hardy in British Isles (Published by John Murray, London, 1987)

2. G. Krassman, Manual of Cultivated Broad-Leaved Trees and Shrubs (London, 1986)

3. V. S. Simagin, G. V. Eremin, Flora and vegetation of Altay, 4(1) (1999)

4. A. V. Lokteva, Polymorphism of bird cherry (Prunus padus L) at a West Siberian sough as form source for introduction and analytic selection (Novosibirsk, 2009) 